\title{
Implementation of a comprehensive nursing care program in the framework of the healthy school strategy in an institution of education of Santa Marta-Colombia
}

\begin{abstract}
The implementation of the Healthy School Strategy (EES) is evaluated through a situational diagnosis of nursing in a Private Education Institution in Santa Marta, Colombia, taking into account the National Guidelines for Healthy School Strategies. Single case study, through two phases: one diagnosis and one intervention. The diagnostic phase is cross-sectional descriptive. The intervention phase was designed and framed in a field of action with the members of the educational community. It is found that the educational Institution does not comply with all the guidelines. Workshops and talks were held that addressed issues of self-care, caring for the environment and life skills (self-esteem, self-knowledge and accident prevention), adequate food, hygiene in food handling and management of diseases prevalent in childhood. The educational institutions, taking into account the regulations of the implementation of the ESS, were opened to new paths that strengthened intersectoral work, seeking to complement the mission of each sector to go beyond child survival and achieve a better quality of life for Girls, boys and young people of schoolage.
\end{abstract}

Volume 5 Issue I - 2018

\author{
Carolina Elena Cortina Navarro, Haidy \\ Oviedo Córdoba \\ Department of Nursing, Universidad de Magdalena, Colombia
}

Correspondence: Carolina Elena Cortina Navarro, Department of Nursing, Universidad de Magdalena, Colombia, Email c.e.cortina@hotmail.com

Received: July 13, 2017 | Published: January 30, 2018

Keywords: healthy school strategy, national guidelines, situational diagnosis of nursing

\section{Introduction}

This article, part of the importance of school and healthy life in the social, psychological and economic field of children of the city of Santa Marta, which brings many benefits and good results, which make the work Nursing becomes a fundamental element in the health-disease process of the community. The general objective is to evaluate, through a situational nursing diagnosis, the implementation of the Healthy School strategy in a Private Education Institution of Santa Marta, taking into account the National Guidelines of Healthy Schools Strategies at the level of promotion and prevention of nursing. In nursing, the main objective of promotion and prevention is to determine actions aimed at avoiding undesirable consequences or states of functioning in the future, through the control of risk factors and the promotion of protective factors of health. Currently, promotion and prevention make up vital issues in health; the research and interventions are many, all with a common denominator: to conduct strategies from different disciplines to achieve a better standard of living for the population in general. ${ }^{1}$ On the other hand, the strategy of healthy schools in Colombia is a national initiative subscribed by the Ministry of Education, Health and by the Family Welfare Institute. This strategy seeks to generate healthy lifestyles, in healthy environments, within a healthy culture. The Healthy School (E.S.) part of the diagnosis of the needs identified by the school community, through a participatory process of teachers, students, family and actors from other sectors. ${ }^{2}$ Similarly, Flórez et al. ${ }^{1}$ affirm that the E.S. constitute a set of health education activities in the school, with the purpose of promoting health and preventing the illnesses of children and teachers, parents, and the surrounding community, from a broad conception of the health-disease process as a promoter of quality of life. ${ }^{1}$ According to the Ministry of Health and Social Protection, ${ }^{3,4}$ it is a strategy for the promotion and protection of health in schools, and an articulating mechanism of interests, wills and multisectoral resources aimed at increasing capacity and opportunities of all the members of the educational communities to improve health, learning, quality of life and opportunities for integral and sustainable human development.

For April and others, ${ }^{5}$ the school becomes a center of convergence in which teachers, students, families and the community work for a common goal: to foster in children the development of life skills that Form as development agents with high self-esteem, creative, selfconfident, innovative, critical and with civic and moral values, which lead them to the constant search for individual and collective wellbeing for the promotion of sustainable human development.

The promotion of health at school is part of a comprehensive vision of the human being that considers people, and especially children and adolescents, within their family, community and social environment. Therefore, one of the main functions of the Healthy School is to transmit knowledge and skills that promote self-care and help prevent risky behavior. To this, the foundation of the Ministry of Public Health and Social Welfare of Paraguay ${ }^{6}$ is added, which states that strengthening the promotion of health in educational institutions that implement the Healthy Schools Strategy involves and commits all the members of the Educational Community to which their actions are expanded. It also contributes to citizen education through the exercise of rights and responsibilities towards the permanent search for the common good. 
For the application and development of the National Guidelines for Healthy Schools Strategies; In Colombia, five components have been defined that favor the promotion of health with an inter-intersectoral approach (individual or personal and group or community) that are the pillars that allow orienting and potentiating an institutional welfare environment. Finally, health has a great influence on society and therefore the evaluation and implementation of the strategy of healthy schools in schools is a responsibility for its participants, since through its guidelines it can be determined in some way, that the Healthy schools strategy promotes teaching and learning in individual and collective health in the educational community.

\section{Methodology}

In an institution of private education, an evaluation of the implementation of the strategy of healthy schools was carried out in an educational institution of Santa Marta, Colombia during the period from March 2016 to May 2016. The research is a unique case study and it was carried out through two phases: one diagnostic and one intervention.

\section{Diagnostic phase}

It is descriptive of cross section, where the work was done with the help of all members of the educational community. And the evaluation was made through observation and a situational diagnosis of nursing that took into account the national guidelines of healthy school strategies established by the Ministry of Health, to propose action plans with proposals aimed at improving the strategy of healthy school in the institution.

These guidelines comprise 5 components:
i. Public Policies and Plans for the Healthy School
ii. Healthy Environments in the School
iii. Empowerment and Social Participation in Health
iv. Education for Health
v. Reorientation of Health Services and Surveillance in public health.

The nursing situational diagnosis allowed through a checklist to identify the national guidelines of healthy school strategies of the Institution related to basic care plans, healthy school policies, changes in school environments, school programs oriented to the promotion of physical activity and eating habits

\section{Intervention phase}

It was designed with the purpose of improving the conditions of the health situation of schoolchildren, through national guidelines of healthy school strategies established by the Ministry of Health. The intervention was framed in a field of action with the members of the educational community.

\section{Collection of information}

The information collected was compiled in a database developed in the Excel 2008 program.

\section{Analysis of data}

The analysis of the information was based on the situational diagnosis of nursing and the performance of an analysis of thematic and teleological content, with a low degree of interpretation, from a didactic pedagogical approach. This involved identifying and describing with the help of a matrix and a checklist the implementation of the healthy schools strategy in the school.

\section{Results}

\section{Diagnostic phase}

When making the situational diagnosis of a private school in Santa Marta, it is found that it does not comply with all the national guidelines for the application and development of healthy school strategies that the Ministry of Social Protection in conjunction with the Ministry of National Education has proposed for schools and colleges to have healthy school services that address factors that influence the health of the educational community. Regarding the components, the educational institution has a basic care plan, which aims at activities, interventions and procedures, health promotion, disease prevention, public health surveillance and control of risk factors. Directed to the educational community. Although it has health promotion programs, the basic care plan of the institution is not given, since it has the infrastructure but does not have trained personnel to provide timely attention to the institution's staff. In addition, there is no articulation of health education with the school curriculum and the IEP. As for healthy environments, the school has agreements with a sports center in Santa Marta «La Caja», in which they emphasize promotion and prevention through sports, swimming and gym. As well as, with the Antares events room for the realization of pedagogical and feeding activities. In the empoderamiento and social participation in health, the department of biology of the school, realizes environmental activities in favor of the care and preservation of the environment nevertheless they are not continuous, which is observed a great necessity in the permanence and strengthening of pedagogical activities and to create environmental awareness, the management and classification of solid waste. Also, a program called "Talent Club" is held in which each student has the option to choose the one with the greatest taste, among which the club of nature scouts is included. It is evidenced that there is no planning, schedule of daily academic activities in school programming that include topics in health. Although the school has a healthy school program, it does not take a sequence of the national guidelines of healthy schools, regarding the eating habits; since in their school store they do not sell healthy foods that students should consume.

Regarding the situation of the students, the population studied was approximately 84 , including children from the precocious, preschool and primary grades with ages between 2 and 12 years ( 36 boys and 48 girls). All the children are affiliated to the General System of Social Security in Health; In terms of oral hygiene, $73 \%(61)$ brush their teeth less than 3 times a day and $26 \%$ do it three or more times a day; $27.3 \%$ of the students have in their vaccination card the incomplete scheme, distributed according to the ages respectively; likewise, $59.5 \%$ (50) of school children have their complete vaccination scheme and $13 \%(11)$ do not have a vaccination card. On the subject of visual acuity, 66\%(56) have normal vision (Normal vision is considered to be between 20/20 and 20/30) and 33\%(28) present some type of visual impairment (measures between 20 and 20/30)./40 and 20/200 are indicative of some visual or ocular problem). In the part of growth and development $57.1 \%(48)$ have a normal weight, $19 \%(16)$ are underweight, $11.9 \%(10)$ are underweight, $7.1 \%(6)$ they are overweight and $4.7 \%(4)$ shows a marked overweight. On the other hand, the situational diagnosis of nursing allowed to corroborate health 
problems such as headaches, where, $9 \%$ of the students manifested the headache due to the non-use of glasses, $13 \%$ manifested the symptom due to low intake. of food, $22 \%$ presented pain from sports, $17 \%$ from having a cold or flu and $39 \%$ from an unknown cause; for a total of $100 \%$ which is equivalent to the 23 students who presented the symptom. Another health problem was stomach pain, $8 \%$ presented gastritis, $25 \%$ of students presented stomach pain from food, and $67 \%$ were due to an unknown cause; for a total of $100 \%$ which is equivalent to the 42 students who presented the symptoms; without presenting absences to classes.

\section{Intervention phase}

Through the strengthening of health promotion and prevention programs, in which the strategies that were used were basically proposals, educational talks and educational workshops aimed at the entire educational community (managers, teachers, parents and students) to establish actions of improvement. There were 9 sessions between lectures and educational workshops with students and teachers. The workshops and lectures that were developed addressed issues of body self-care, care of the environment and life skills (self-esteem, self-knowledge and accident prevention), adequate food, hygiene in handling food and handling diseases prevalent in childhood.

\section{Discussion}

PAHO, together with the Ministry of Social Protection, the Ministry of Education and the Ministry of Environment, Housing and Territorial Development, believe that: "it is necessary to articulate strategies that promote and encourage the creation of healthy environments for the improvement of conditions of life of the population and in this way influence their welfare. For this reason, Colombia has welcomed the regional initiatives of Healthy School and Healthy Housing, promoted by the Pan American Health Organization, Regional Office of the World Health Organization, PAHO/WHO. ${ }^{3}$

In the present work, the results show that the school despite having an educational plan based on the healthy school strategy where the guidelines for its fulfillment are presented; the applicability of promotion and prevention programs throughout the institution is needed. Also, it has a nursing space that does not have enough resources for the needs it presents. More educational projects are needed in terms of the promotion and prevention of health, for example: oral hygiene, healthy eating plan, among others. Cárdenas, Suarez et al. ${ }^{7}$ affirm in their research that: "Health Promotion recognizes that health is not only the health sector, but requires an intersectoral approach since it goes beyond the absence of disease and it is configured as the maximum well-being in which social and economic determinants related to food, access to drinking water and basic sanitation, education, employment, stable ecosystem and sustainable resources converge, requirements for health established in the Ottawa Charter. ${ }^{8}$ Therefore, it can be said that for the school the implementation of the healthy school strategy must become a reason or a reason to address issues that strengthen knowledge about the health and well-being of the entire educational community, and this experience changes of consciousness at a social, cultural, biological, etc. level According to Ramos and others ${ }^{9}$ in health, interventions imply the generation of changes in the current conception and management of the different public health policies and strategies that are carried out, in order to contribute to the generation of active, managerial and responsible for their own health. In addition, Lamus et al. ${ }^{2}$ state that healthy schools conceptually admit that for the promotion of health it is necessary to change the conditions of life as the way of life. On the other hand, in the part of the health profile, it is outdated since there is no evidence of growth and development in children under 5 years of age and vaccination. At the same time, the interventions reflected that there are children with a higher body mass index for height and age and children with a lower body mass index for height and age; which were underweight (some defendants) or overweight (some defendants). Consequently, with the results of the health profile update, educational measures were taken for the alterations that were found in growth and development.

The Ministry of Education ${ }^{10}$ published in a link that the situation of obesity and overweight in children and adolescents is the responsibility of both families and schools, because in these places students passed around 8 hours a day of their active life, and many receive school feeding.

Given the above, in Colombia according to Rojas ${ }^{11}$ the National Survey of Nutritional Situation (ENSIN 2010), the prevalence of overweight or obesity has increased, by $25.9 \%$ in the last five years in children and adolescents, with reference to that the prevalence of overweight tends to increase with the age and level of SISBEN, highlighting that physical inactivity and inadequate eating habits are the main causes of this situation. ${ }^{12}$

Likewise, Salinas, Correa and $\mathrm{Vio}^{13}$ declare that the Law on Nutritional Composition of Foods and its Advertising in Chile in its 4th article establishes that: "Pre-school, basic and middle education establishments in the country must include, in all their levels and modalities of teaching, didactic and physical activities that contribute to developing habits of healthy eating and warn about the harmful effects of an excessive diet in fats, saturated fats, sugars, sodium and other nutrients whose consumption in certain quantities or volumes can represent a risk to health".

In that same context, Colombia should not be left behind in its policies for the feeding and nutrition of children and schoolchildren. It is important to state that the Ministry of Health ${ }^{14}$ in its ABECÉ Program conceptualizes healthy eating as: that which satisfies the needs of energy and nutrients in all stages of life considering its physiological state and growth rate; promotes the supply of nutrients from the mother to the fetus, the practice of breastfeeding and includes foods rich in nutrients and adequate complementary feeding; providing a complete, balanced, sufficient, adequate, diversified and safe diet that prevents the appearance of diseases associated with a deficient or excessive intake of energy and nutrients. Finally, it should be noted that the educational institution promotes the development of healthy lifestyles, as well as maintaining a psychosocial environment with interpersonal quality and warmth. They maintain the integrity and safety of students through a project "use of time free". The institution has a program of prevention and promotion of a healthy coexistence and emotional stability led by the coordination of coexistence and psychology, which generates maintaining in the students, a mental and psychosocial health. Students have oral hygiene habits and hand washing before and after lunch.

\section{Conclusion}

Within the results at a general level, it can be concluded that it is evident in the school studied the non-compliance with the national guidelines for healthy school strategies established by the Ministry of Health. The educational establishment does not have sports and 
play areas in its infrastructure for the recreation of children, but has an agreement with a site that provides sports services. The institution has programs for prevention and promotion of a healthy coexistence and emotional stability led by the coordination of coexistence and psychology, which generates a mental and psychosocial health in the students. Finally, it is worth noting that the implementation of the strategy of healthy schools, achieves that in schools mitigate in some way with certain social, economic, political and cultural problems related to the health of the educational community. The educational institutions, taking into account the regulations of the implementation of the healthy school strategy, opened up new paths and strengthened the intersectoral work, seeking to complement the mission of each sector to go beyond child survival and achieve better quality of life for girls, boys and young people of school age.

\section{Thanks}

In a special way; the entire educational community (principals, teachers, parents and students) of the school is thanked for their collaboration and management in the realization of the different educational activities that were carried out. In turn, they made possible the results that are evident in this work, to all of them many thanks.

\section{Acknowledgements}

None.

\section{Conflict of interest}

The author declares no conflict of interest.

\section{References}

1. Flórez L, Duran E, Eslava J, et al. Tres estudios de análisis de las actividades de salud escolar y de las condiciones organizacionales asociadas, en escuelas distritales de bogotá. Típica, Boletínelectrónico de salud escolar. 2006;2(1).

2. Lamus F, Jaimes C, Castilla M, et al. Hacia una escuela saludable: una experiencia de integración de los agentes educativos en torno a la calidad de vida. Educación y Educadores. 2003.
3. OPS. Ministerio de protección social, Ministerio de educación nacional y ministerio de ambiente, vivienda y desarrollo social. Lineamientos nacionales para la aplicación y el desarrollo de las estrategias de entornos saludables; 2006

4. Ministerio de salud y organización panamericana de la salud. Fortalecimiento de la estrategia de entornos saludables y su implementación, en el marco del plan nacional de desarrollo y compromisos; 2012.

5. Abril E, Rascón C, Bonilla $\mathrm{P}$, et al. Promoción de hábitos saludables en escolares de Hermosillo, Sonora, México. Revista Cubana de Higiene y Epidemiologia. 2012;50(3):354-364.

6. Ministerio de salud pública y bienestar social. Guía de gestión de la estrategia de escuela saludable, Asunción, OPS; 2011.

7. Cárdenas L, Suárez C, Agudelo N. Implementación de la estrategia escuela saludable. Una alianza intersectorialInvestigación y educación en enfermería; 2010.

8. Organización panamericana de la salud. Carta de Ottawa de 1986; 2010.

9. Ramos P, Pasarín M, Artazcoz L, et al. Escuelas Saludables y participativas: evaluación de una estrategia de salud pública. Revista Gaceta Sanitaria. 2013;27(2):104-110.

10. Ministerio de educación. Obesidad en infantes y adolescentes, a propósito del día nacional de la lucha contra la obesidad y el sobrepeso; 2016.

11. Rojas D. Percepción de alimentación saludable, hábitos alimentarios estado nutricional y practica de actividad física en población de 9-11 años del colegio CEDID, Ciudad bolívar, Bogotá. Tesis de pregrado pontifica universidad javeriana; 2011.

12. ENSIN. Instituto colombiano de bienestar familiar, Resumen ejecutivo encuesta nacional de la situación nutricional en colombia; 2010.

13. Salinas J, Correa F, Vio F. Marco normativo para promover una alimentación saludable en escuelas básicas de Chile. Revista Chilena de nutrición. 2013;40(3).

14. Ministerio de Salud Abecé de la alimentación saludable; 2015. 